\title{
INFLUENCES OF PROPRANOLOL ON OUTCOMES OF SEVERELY ADULT BURN PATIENTS
}

\author{
Phan Quoc Khanh', Nguyen Hai An², Nguyen Nhu Lam² \\ ${ }^{1}$ Military Medical Hospital 4/Military Region 4 \\ ${ }^{2}$ Le Huu Trac National Burn Hospital
}

\begin{abstract}
SUMMARY
This study evaluated the influence of Propranolol on outcomes of severely adult burn patients. A randomized controlled trial was on 124 patients who were divided into two groups: Control group $(A)$ received conventional treatment, study group (B) was treated with Propranolol.

The result indicated that, along the time, the heart rate of the study group steadily decreased and was significantly lower than that of the control group (90.24 \pm 11.51 vs. $101.43 \pm 13.69 \mathrm{bpm} ; p<0,01$ at $28^{\text {th }}$-day afterburn). From the $7^{\text {th }}$ day onward afterburn, the body temperature of both groups decreased and the temperature was significantly lower than that in the control group $(p<0.05)$. Hematological parameters, mean arterial pressure, complication rate and treatment time were not remarkably different between the two groups $(p>0.05)$. There was also no significant difference in mortality between groups (19.35\% vs $17.74 \%$; $p>0.05)$.
\end{abstract}

Keywords: Propranolol, severe burn, adult, outcomes

\section{INTRODUCTION}

The hypermetabolic state in burn patients is considered to be the greatest of any other type of trauma or surgery. Prolonged hypermetabolism, if untreated will lead to increased energy requirements, immunity depression, increased risk of infection, retarded wound healing, prolonged recovery time, increased rate of complications and death [1].

Corresponding author: Nguyen Nhu Lam, Le Huu Trac National Burn Hospital. Email: lamnguyenau@yahoo.com Ngày nhận bài: 26/11/2021; Ngày nhận xét: 20/12/2021; Ngày duyệt bài: 30/12/2021 https://doi.org/10.54804/yhthvb.6.2021.91
Propranolol is a non-selective betablocker that is indicated for the treatment of post-burn hypermetabolism and has been extensively studied and used safely in children with severe burns. However, there was evidence that propranolol may reduce immune function and the body's resistance to infections [2], [3]. In adult patients with severe burns, there were limited studies with results were varied between studies, especially regarding the effectiveness of propranolol. The aim of this study was to determine the effect of propranolol on progression and mortality in adult patients with severe burns treated at the National Burn Hospital. 


\section{PATIENTS AND STUDY METHODS}

A prospective study was carried out on 124 adult patients with severe burns treated at the Intensive care unit (ICU), National Burn Hospital from August 2016 to August 2018 with the following criteria: Age from 16 to 60 years old, hospitalized within the first 72 hours after burn, burn extent $\geq$ $20 \%$ total body surface area (TBSA), without associated illness, injury or contraindications to propranolol. Patients were randomly divided into 2 groups (62 patients each). Group A was managed according to the routine protocol of the National Burn Hospital; Group B was treated with Propranolol from the $3^{\text {rd }}$ day afterburn according to the reported protocol by Herdon DN, et al 2012 [4].
Accordingly, the starting dose of Propranolol was $20 \mathrm{mg} /$ time, 3 times per day by mouth or by nasogastric tube. The dose was adjusted to achieve the goal of reducing the initial heart rate by $15-20 \%$. The outcome measures included heart rate, mean arterial pressure, body temperature, red blood cell, hemoglobin $(\mathrm{Hb})$, white blood cell and an absolute number of lymphocytes on the $3^{\text {rd }}$, $7^{\text {th }}, 14^{\text {th }}, 21^{\text {st }}$ and $28^{\text {th }}$-day after-burn. In addition, complications, duration of antibiotic use, stay duration in the intensive care unit (ICU), length of hospital stay and mortality rate were also recorded.

The data were analyzed using Stata 14.0 software, $p<0.05$ was considered to be statistically significant.

\section{RESULTS}

Table 1. Patients characteristics

\begin{tabular}{|l|c|c|c|}
\hline \multicolumn{1}{|c|}{ Characteristic } & Group A & Group B & p \\
\hline Age (year) & $35.19 \pm 10.90$ & $35.87 \pm 9.43$ & 0.71 \\
\hline Burn extent (\%TBSA) & $50.90 \pm 17.44$ & $50.05 \pm 19.68$ & 0.79 \\
\hline Deep burn area (\%TBSA) & $19.34 \pm 16.34$ & $19.35 \pm 18.30$ & 0.99 \\
\hline Inhalation injury, n(\%) & $6(9.70)$ & $8(12.90)$ & 0.57 \\
\hline Admission time postburn (h) & $5(3-9)$ & $4(3-7)$ & 0.45 \\
\hline
\end{tabular}

The patients in both groups were severe burns with an average burn surface area of $50.90 \pm 17.44 \%$ TBSA in group A and $50.05 \pm 19.68 \%$ in group $B$. Age, burn extent, deep burn area, rate of inhalation injury as well as the time of hospitalization after burns were not statistically significant between two groups ( $p>0.05)$.

On the $3^{\text {rd }}$ day after the burn, the mean heart rate of the 2 groups was high and the difference was not statistically significant with $p>0.05$. From the $7^{\text {th }}$ to the $28^{\text {th }}$-day afterburn, the heart rate of patients in group $B$ gradually decreased and was always lower than that in group $A$ with $p<0.01$. On the $28^{\text {th }}$ day postburn, the heart rate of group B was $90.24 \pm 11.51$ beats $/ \mathrm{min}$, while the heart rate of group A was 101.43 \pm 13.69 beats $/ \mathrm{min}$. 


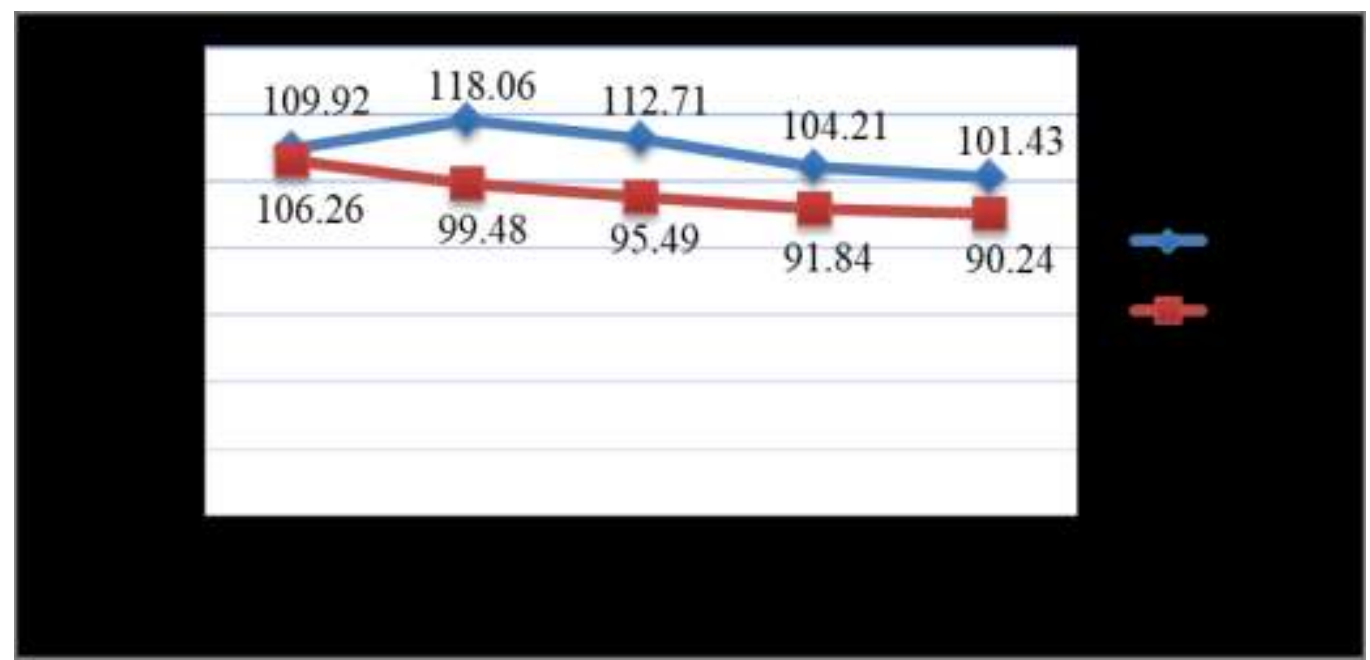

Figure 1. Change of heart rate along with the time afterburn

Table 2. Change of mean arterial pressure $(\mathrm{mmHg})$ along the time

\begin{tabular}{|c|c|c|c|}
\hline Time & Group A & Group B & $p$ \\
\hline $3^{\text {rd }}$ day & $89.02 \pm 12.73$ & $88.17 \pm 13.13$ & 0.71 \\
\hline $7^{\text {th }}$ day & $90.45 \pm 13.13$ & $85.93 \pm 6.20$ & 0.015 \\
\hline $14^{\text {th }}$ day & $87.13 \pm 7.46$ & $85.84 \pm 5.48$ & 0.29 \\
\hline $21^{\text {st }}$ day & $87.47 \pm 5.23$ & $85.94 \pm 5.29$ & 0.16 \\
\hline $28^{\text {th }}$ day & $87.81 \pm 3.96$ & $86.03 \pm 3.93$ & 0.08 \\
\hline
\end{tabular}

The mean arterial blood pressure of both groups at all time points was within physiological limits ( $>65 \mathrm{mmHg}$ ). Except for the 7 th day after the burn, mean arterial blood pressure at all time points was not significantly different between the two groups $(p>0.05)$.

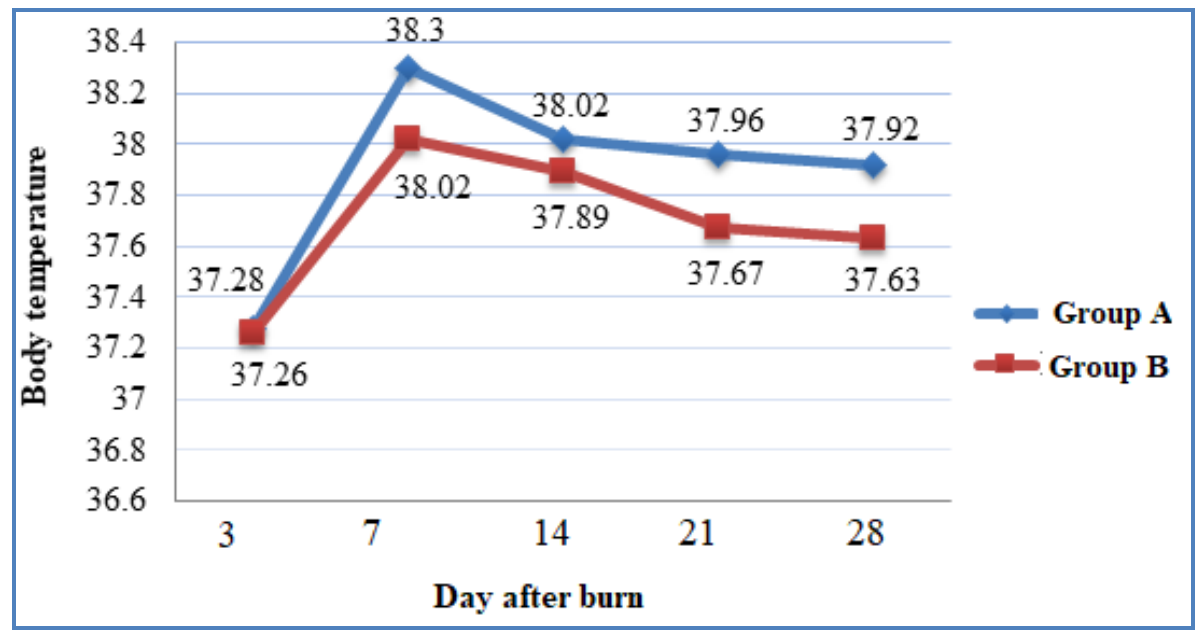

Figure 2. Change of body temperature 
On the $3^{\text {rd }}$ day after the burn, the body in group $B$ gradually decreased and was temperature of the 2 groups was not always lower than group $A$, the difference statistically significant with $p>0.05$. From was statistically significant at the time of $7^{\text {th }}$, day $7^{\text {th }}$ to $28^{\text {th }}$, the temperature of patients $21^{\text {st }}$, and $28^{\text {th }}$ day with $p<0.05$.

Table 3. Change of red blood cells and $\mathrm{Hb}$

\begin{tabular}{|c|c|c|c|c|c|c|}
\hline \multirow{2}{*}{ Time } & \multicolumn{3}{|c|}{ Red blood cell (T/L) } & \multicolumn{3}{c|}{ Hb (g/L) } \\
\cline { 2 - 7 } & Group A & Group B & $\mathrm{p}$ & Group A & Group B & $\mathrm{p}$ \\
\hline $3^{\text {rd }}$ day & $5.39 \pm 0.85$ & $5.45 \pm 0.76$ & 0.66 & $162.85 \pm 22.63$ & $161.66 \pm 21.11$ & 0.76 \\
\hline $7^{\text {th }}$ day & $3.50 \pm 0.67$ & $3.54 \pm 0.77$ & 0.80 & $106.43 \pm 20.05$ & $106.22 \pm 21.66$ & 0.95 \\
\hline $14^{\text {th }}$ day & $3.29 \pm 0.67$ & $3.38 \pm 0.71$ & 0.51 & $99.98 \pm 19.90$ & $101.49 \pm 20.64$ & 0.69 \\
\hline $21^{\text {st }}$ day & $3.19 \pm 0.56$ & $3.31 \pm 0.57$ & 0.30 & $93.97 \pm 21.71$ & $98.45 \pm 17.72$ & 0.28 \\
\hline $28^{\text {th }}$ day & $3.31 \pm 0.65$ & $3.29 \pm 0.43$ & 0.88 & $97.96 \pm 19.37$ & $96.82 \pm 14.17$ & 0.79 \\
\hline
\end{tabular}

The number of red blood cells and $\mathrm{Hb}$ level over time in the two groups were similar and the difference was not statistically significant $(p>0.05)$.

Table 4. Change of white blood cells and Lymphocytes

\begin{tabular}{|c|c|c|c|c|c|c|}
\hline Time & \multicolumn{3}{|c|}{ White blood cell (G/L) } & \multicolumn{3}{c|}{ Lymphocytes (G/L) } \\
\hline & Group A & Group B & $\mathrm{p}$ & Group A & Group B & $\mathrm{p}$ \\
\hline $3^{\text {rd }}$ day & $9.73 \pm 3.41$ & $10.62 \pm 10.77$ & 0.17 & $1.14 \pm 0.37$ & $1.21 \pm 0.44$ & 0.39 \\
\hline $7^{\text {th }}$ day & $13.87 \pm 4.17$ & $13.96 \pm 1.20$ & 0.91 & $1.46 \pm 0.55$ & $1.47 \pm 0.56$ & 0.88 \\
\hline $14^{\text {th }}$ day & $14.46 \pm 4.85$ & $12.77 \pm 4.20$ & 0.049 & $1.69 \pm 0.64$ & $1.83 \pm 0.68$ & 0.26 \\
\hline $21^{\text {st }}$ day & $12.06 \pm 4.32$ & $10.56 \pm 4.09$ & 0.09 & $1.79 \pm 0.76$ & $1.82 \pm 0.73$ & 0.88 \\
\hline $28^{\text {th }}$ day & $10.27 \pm 4.77$ & $10.51 \pm 2.70$ & 0.81 & $2.19 \pm 0.98$ & $1.94 \pm 0.55$ & 0.24 \\
\hline
\end{tabular}

The number of peripheral white blood cells in both groups was high right after admission, increased at 7 th and $14^{\text {th }}$-day afterburn, then gradually decreased but still higher than the normal limit (4 - 9G/L) with the difference between the two groups was not statistically significant $(p>0.05)$. The absolute number of peripheral blood lymphocytes in the two groups increased gradually until the 28th-day after-burn. In group $A$, it was $2.19 \pm 0.98 \mathrm{G} / \mathrm{L}$ and in group $B$ was $1.94 \pm 0.55 \mathrm{G} / \mathrm{L}$ and the difference was also not statistically significant across groups ( $p>0.05)$. 
Bảng 5. Treatment outcomes

\begin{tabular}{|l|l|c|c|c|}
\hline \multicolumn{2}{|c|}{ Complications } & Group A & Group B & p \\
\hline \multirow{3}{*}{ Time (day) } & Used antibiotic & $21(17-27.25)$ & $21(14-28.25)$ & 0.47 \\
\cline { 2 - 5 } & ICU stay & $16.5(10.75-24.0)$ & $15(9-21.75)$ & 0.33 \\
\cline { 2 - 5 } & Hospitalization & $32(22.5-43.25)$ & $31.5(20-45.75)$ & 0.67 \\
\hline ARDS*, n (\%) & $5(8,06)$ & $2(3.23)$ & 0.24 \\
\hline Acute renal failure, $\mathrm{n}(\%)$ & $9(14,52)$ & $8(12.90)$ & 0.79 \\
\hline Sepsis, $\mathrm{n}(\%)$ & $2(3,23)$ & $6(9.68)$ & 0.14 \\
\hline Septic shock, $\mathrm{n}(\%)$ & $9(14,52)$ & $14(22.58)$ & 0.24 \\
\hline Multiple organ failure, $\mathrm{n}(\%)$ & $10(16,13)$ & $13(20.97)$ & 0.48 \\
\hline Death, $\mathrm{n}(\%)$ & $11(17,74)$ & $12(19.35)$ & 0.81 \\
\hline
\end{tabular}

The duration of used antibiotics, duration of ICU and hospital stay were not significantly different between the two groups $(p>0.05)$. The rate of ARDS complications in group $A$ tended to be higher $(8.06 \%$ versus $3.23 \%)$ but the difference was not remarkably significant ( $p$ $=0.24$ ). Other complications such as sepsis, septic shock, multiple organ failure and mortality rates were also not statistically significantly different with $p>0.05$.

\section{DISCUSSION}

Severe burns cause dysfunction of many organs including e cardiovascular system. Hypermetabolic state after-burn results in increased heart rate, cardiac output. The long-lasting disorder leads to reduced efficiency of myocardial oxygen consumption and causes heart failure. Propranolol is a non-selective beta-blocker that reduces heart rate, cardiac output, increases diastolic volume, and reduces myocardial oxygen consumption. A study by Williams FN et al. (2011) showed that besides these effects, Propranolol did not significantly influence cardiac output index and mean arterial blood pressure as compared with the control group [5].

Lunawat A. et al (2015) studied 50 adult burn patients, divided into 2 groups with and without Propranolol found that, in the Propranolol group, the mean heart rate on admission was $131 \pm 9.36$ beats $/ \mathrm{min}$ and reduced to $94.52 \pm 6.65$ beats $/ \mathrm{min}$ at the $14^{\text {th }}$ day after the burn. Meanwhile, in the non-Propranolol group, the mean heart rate at hospital admission was $130.32 \pm$ $8.67 \mathrm{times} / \mathrm{min}$ and that was $115.04 \pm 9.93$ $\mathrm{CK} / \mathrm{min}$ the $14^{\text {th }}$-day afterburn, the difference was statistically significant $(p<$ 0.05). AS compared with admission, mean heart rate during sleep time decreased by $28 \%$ and $27 \%$ on day 7 and day 14 after the burn in the Propranolol group, respectively, while in the non-Propranolol group, the heart rate only decreased by $12 \%$ and $11 \%$, respectively [6].

A report by Herndon DN et al. (2012) showed that the heart rate of burn patients at the time of admission increased 1.7 times compared to normal healthy people at the same age. Along the time from $1^{\text {st }}$ week to $12^{\text {th }}$ month after burns, the heart 
rate of the Propranolol group decreased statistically significantly compared with the control group. However, in the period from 1 to 3 months after burns, the heart rate of burn patients with or without Propranolol still increased by $120-140 \%$ compared to normal healthy subjects [4].

The results of our study showed that, at the time of admission, the heart rate of the 2 groups of patients taking and not taking Propranolol was elevated and the difference was not statistically significant $(p>0.05)$. From the $7^{\text {th }}$ to $28^{\text {th }}$-day afterburn, the heart rate of the Propranolol group gradually decreased and was always lower than that of the non-Propranolol group ( $p<0.01$ ).

For burn patients, many studies reported that using Propranolol as the target of reducing the heart rate by $15-20 \%$ did not significantly affect blood pressure compared to the control group. Our study showed that the mean arterial pressure at the time of both groups was always within physiological limits. Similarly, the results of the study by Herndon DN et al (2012) found that the mean arterial pressure in the propranolol group at the $2^{\text {nd }}$ and $4^{\text {th }}$ week after burns decreased significantly compared with the control group but did not increase the number of patients with mean arterial pressure $<65 \mathrm{mmHg}$ [4].

Severe burns alter the temperature control centers, hyper sympathetic, increase serum catecholamine levels, stimulate the body to produce heat. Lunawat $A$ et al (2015) found that the body temperature of the group without Propranolol was $99.1 \pm$ $0.80^{\circ} \mathrm{F}$ and $98.95 \pm 0.7^{\circ} \mathrm{F}$ on $1^{\text {st }}$ and $14^{\text {th }}$ day afterburn, while the body temperature of the Propranolol group was $99.1 \pm 0.78^{\circ} \mathrm{F}$ and $98.5 \pm 0.21^{\circ} \mathrm{F}$ respectively, the difference was statistically significant [6].
The results of our study were similar to this study. From the $7^{\text {th }}$ to the $28^{\text {th }}$-day afterburn, the body temperature of the propranolol group gradually decreased and was always lower than that of the non-Propranolol group. On the $28^{\text {th }}$ day after the burn, the body temperature of the Propranolol group was $37.63 \pm 0.34^{\circ} \mathrm{C}$, while the body temperature of the Propranolol group was $37.92 \pm 0.47^{\circ} \mathrm{C}$, the difference was statistically significant with $p<0.05$.

Only a few studies have shown that Propranolol improves hospital stay compared to controls [6]. Most of the studies showed that there was no statistically significant difference in the number of hospital stays between the propranolol and non-Propranolol groups.

In our study, the study subjects were patients with severe burns, large areas of deep burns, who had to undergo long-term treatment from shock protection, skin graft surgery, burn care to recovery. function, most of the patients who were saved had a rather long hospital stay. There was no statistically significant difference between the duration of antibiotic use, the duration of treatment in the ICU, and the length of hospital stay between the groups taking and not taking Propranolol.

Sepsis complications and the role of Propranolol after severe burns have been mentioned by many studies. Most of the studies showed that there was no difference in the incidence of sepsis between groups with or without using Propranolol. Similarly, the results of our study showed that there was no difference in the rate of sepsis between groups. Not only that, but some studies also showed that Propranolol could reduce the burn wound infection, 
bacteremia, and inflammatory response compared to the control group.

Research by Kobayashi M et al (2011) showed that propranolol increased conversion of monocytes from M2b type (IL-10 production, poor bactericidal ability) to $\mathrm{M} 1$ type (production of $\mathrm{IL}-12$, higher bactericidal ability) thereby reducing bacterial infections [7]

The results of our study also showed that rates of other complications during treatment such as acute renal failure, ARDS, multiple organ failure, septic shock, were not statistically significant between the group with and without propranolol.

Most of the studies showed that mortality was closely related to burn extent and there was no difference between the group taking and not using Propranolol. Our study was basically consistent with the above studies, the mortality rate is not statistically significant between the group taking and not using Propranolol. However, the study by Lunawat A. et al (2015) indicated that Propranolol was effective in reducing mortality in burn patients [6]. It is necessary to conduct further trials determining the clinical effects of Propranolol in adult burn patients, especially on complication and mortality rates.

\section{CONCLUSION}

In adult patients with severe burns, Propranolol significantly reduces heart rate and body temperature as compared to the control group but did not cause significant changes in blood pressure. Duration of treatment, complication and mortality rate was not significantly different between the two groups with or without propranolol treatment.

\section{REFERENCES}

1. Jeschke MG, Norbury WB, Finnerty CC, et al. Propranolol does not increase inflammation, sepsis, or infectious episodes in severely burned children. J Trauma 2007; 62(3):676-681.

2. Oberbeck R. Therapeutic implications of immune-endocrine interactions in the critically ill patients. Curr Drug Targets Immune Endocr Metabol Disord 2004; 4:129-139.

3. Oberbeck R, Schmitz D, Wilsenack K, et al. Adrenergic modulation of survival and cellular immune functions during polymicrobial sepsis. Neuroimmunomodulation 2004; 11:214-223.

4. Herndon DN, Rodriguez NA, Diaz EC, et al. Long-term propranolol use in severely burned pediatric patients: a randomized controlled study. Annals of surgery 2012; 256(3):402-411.

5. Williams FN, Herndon DN, Kulp GA, et al. Propranolol decreases cardiac work in a dosedependent manner in severely burned children. Surgery 2011; 149(2):231-239.

6. Lunawat A, Vishwani A, Datey $\mathbf{S}$, et al. Modulation of hypermetabolism in burn patient by administration of propranolol in the first two weeks and assessing its effect by using clinical and biochemical parameters. Indian Journal of Burns 2015; 23(1):19-25.

7. Kobayashi M, Jeschke MG, Asai $A$, et al. Propranolol as a modulator of M2b monocytes in severely burned patients. Journal of leukocyte biology 2011; 89(5):797-803. 